\title{
Minimally Invasive Liver Surgery: Has it Achieved the Standard of Care?
}

\author{
Sean P. Cleary \\ Department of Surgery, Mayo Clinic, Rochester, MN
}

Minimally invasive surgery (MIS) has revolutionized many procedures over the past three decades. The rapid adoption of laparoscopic cholecystectomy in the 1980s altered our approach to gallbladder surgery over a very short period of time. This experience has led us to learn from the tremendous advantages for patients from a MIS approach in terms of reduced pain and enhanced recovery, but also the potential hazards resulting from rapid shifts in surgical practice with regards to training and safety. Since then, the adoption of MIS approaches to a variety of indications has required stepwise demonstration of at least equivalence in feasibility, safety, and cost, as well as shortand long-term patient outcomes of MIS compared with open surgery.

Since the first publications, the adoption of minimally invasive liver resection (MILR) has been slow compared with the rate at which MIS approaches have been incorporated into luminal (gastric, colon, bariatric) and other solid organ procedures (prostate, adrenal). ${ }^{1,2}$ This slow adoption has persisted despite expanding indications and increasing literature in the field. ${ }^{3,4}$ Consensus conferences in 2008, 2014, and 2017 established important principles in the field, including the suggestion of dual training in advanced MIS and liver surgery, documented the safety, and short-term equivalence of MILR and suggested that MILR should be the standard of care for minor liver resections. $^{5-7}$

Based on international data, primary liver cancer is the most common indication for MILR, whereas metastatic disease may predominate as an indication in North

(C) Society of Surgical Oncology 2018

First Received: 20 December 2017;

Published Online: 21 February 2018

S. P. Cleary

e-mail: cleary.sean@mayo.edu
America and Europe.$^{8-10}$ The high use of MILR for primary liver malignancy may be the result of several factors, including patient selection as surgery is generally indicated for solitary lesions; geographic trends in both the incidence of primary liver cancer and MIS expertise; and the benefits of MILR in patients with chronic liver disease while being countered by the difficulties of liver surgery in patients with fibrosis or cirrhosis. Many publications have established the feasibility, safety, and long-term outcomes of MILR in primary liver cancer compared with open procedures. ${ }^{11,12}$ MILR results in decreased pain, length of hospital stay, and overall morbidity with comparable rates to open procedures of curative resection, complications, and oncologic outcomes, including disease-free and overall survival.

While the consensus conferences and publications from expert centres has reported the benefit of MILR, population-based or "real-world" evidence of its implementation has indicated low rates of adoption of MILR outside of specific centres. Goutte et al. demonstrated that for leftlateral segment resection only approximately $30 \%$ of procedures were performed laparoscopically. ${ }^{13}$ While this may seem reasonable, it is worth noting that left-lateral resections are among the most straightforward MILR procedures by difficulty, and these data were derived from France, a nation that has been among the leaders in MILR ${ }^{14,15} \mathrm{He}$ et al. combined data from the National Impatient Sample (NIS) and National Surgical Quality Improvement Project (NSQIP). ${ }^{9}$ While the data demonstrated that overall complications and in-hospital mortality for MILR was the same (NSQIP) or lower (NIS) than open surgery, MILR accounted for only 3.5 and $4.8 \%$ of liver resections. The median hospital volume for MILR in the NIS was 3.5 cases per year. While there was a slight nonstatistically significant increase in MILR over time, these data indicated that in centres participating in NIS/NSQIP, MILR is rarely 
applied to any great extent on a wider scale outside specific centres of excellence.

Varley et al. have provided more in-depth assessment by focusing on patient undergoing resection for primary liver cancer in the National Cancer Data Base (NCDB). ${ }^{16}$ While the proportion of liver resections done via a MIS approach was encouraging (20\%), the decision for an open versus MIS approach appeared to depend significantly on where the patient was seen, indicating that surgeons' comfort and familiarity with MILR had a significant impact on the approach taken in addition to patient or tumour factors. This is significant, because less than half of the contributing centres performed any MILR cases. Interestingly, older patient age and higher comorbidity was associated with MILR. While there may be many interpretations of these results, higher risk patients may be preferentially offered MILR due to a bias among surgeons that MILR is associated with lower risk and less morbidity than the comparable open operation.

Among the $48 \%$ of centres that did perform MILR, they were equally prevalent among academic and comprehensive community cancer programs. The individual centre volume for MILR was low, with a median of two cases per year; only 5\% of centres performed more than ten cases per year. Perhaps the most interesting finding is that the proportion of cases done via the MIS approach did not differ between low-, medium-, and high-volume liver resection programs. Varley et al. explored the well-established volume-outcome relationship in liver surgery as it pertains to MILR. ${ }^{16}$ Patient factors and hospital volume were all associated with 90-day mortality, whereas there was no difference between MIS and open liver resection in mortality, complications, or oncologic outcomes. It is noteworthy that use of MILR at low-volume centres did not alter the volume-outcome relationship further reinforcing that systems factors are more likely to play a role than surgeon-specific or technical factors in determining shortterm outcomes.

The recent Iwate consensus conference and Varley et al. both stated that MILR is the standard of care for minor liver resection. ${ }^{6,16}$ However, the population-based data indicate that MILR has not gained widespread acceptance and its adoption lags significantly behind MIS in other domains. It is unclear why this evolution is harder in liver surgery than other procedures. The two largest barriers are likely training and clinical volume in liver surgery. There is widespread consensus that MILR requires advanced laparoscopic skills as well as significant experience in hepatic anatomy and resection. Because the proportion of appropriate cases for MILR may be 25-50\%, even in experienced hands a reasonable volume of liver surgery is required to generate enough suitable cases to develop a significant MILR experience and progress along a very difficult learning curve. ${ }^{17}$ The declining use of major hepatectomy in favour of parenchymal-preserving procedures will certainly limit the progress of MIS hepatic lobectomy even in large-volume centres. The data presented by Varley and others show that even among highvolume liver programs there is a great deal of skepticism of MILR and a low number of procedures performed at these centres. ${ }^{16}$ This undoubtedly affects the MILR experience in fellowship training, which will further perpetuate the slow progress in this field.

The reasons for this scepticism are unclear, whether it is inertia among surgeons to changes in practices or a perceive lack of benefit to MILR. While the existing data on the benefits of MILR are significant and the data are consistent and compelling, it is predominantly derived from retrospective series from isolated centres. The improved outcomes in terms of morbidity, complications, hospital stay, and enhanced recovery with no compromise in oncologic outcomes are important and relevant factors to patients. While prospective, randomized data have not been required to promote MIS surgery in other domains, the recent Oslo CoMET study may help to promote MILR in this regard. ${ }^{18}$ Regrettably, proper randomized prospective trials are costly and logistically prohibitive; therefore, we need to find other ways to address this shortfall to convince surgeons of the benefit MILR. There is a strong commitment from the MILR community to improve the quality of evidence and, combined with enhanced training and improvements in technology, to facilitate adoption. The hope is that MILR will be available to more patients in the coming years.

\section{REFERENCES}

1. Gagner, M, Rheault, M, Dubuc J. Laparoscopic partial hepatectomy for liver tumor. Surg Endosc. 1993; 6:699.

2. Cherqui D, Husson E, Hammoud R, et al. Laparoscopic liver resections; a feasibility study in 30 patients. Ann Surg. 2000;232:753-62.

3. Hibi T, Cherqui D, Geller DA, Itano O, Kitagawa Y, Wakabayashi G. Expanding indications and regional diversity in laparoscopic liver resection unveiled by the International Survey on Technical Aspects of Laparoscopic Liver Resection (INSTALL) study. Surg Endosc. 2016;30(7):2975-83.

4. Nguyen KT, Gamblin TC, Geller DA. World review of laparoscopic liver resection-2804 patients. Ann Surg. 2009;250(5):831-41.

5. Buell JF, Cherqui D, Geller DA, et al. The international position on laparoscopic liver surgery: the Louisville Statement, 2008. Ann Surg. 2009;250:825-30.

6. Wakabayashi G, Cherqui D, Geller DA, et al. Recommendations for laparoscopic liver resection: a report from the second international consensus conference held in Morioka. Ann Surg. 2015;261(4):619-29.

7. Abu Hilal M, Aldrighetti L, Dagher I, et al. The Southampton consensus guidelines for laparoscopic liver surgery: from 
indication to implementation. Ann Surg. 2017. https://doi.org/10. 1097/sla.0000000000002524.

8. Ciria R, Cherqui D, Geller DA, et al. Comparative short-term benefits of laparoscopic liver resection: 9000 cases and climbing. Ann Surg. 2016;263(4):761-77.

9. He J, Amini N, Spolverato G, et al. National trends with a laparoscopic liver resection: results from a population-based analysis. HPB (Oxford). 2015;17(10):919-26.

10. Berardi G, Van Cleven S, Fretland Å, et al. Evolution of laparoscopic liver surgery from innovation to implementation to mastery: perioperative and oncologic outcomes of 2238 patients from 4 European specialized centers. $J$ Am Coll Surg. 2017;225(5):639-49.

11. Lee JJ, Conneely JB, Smoot RL, et al. Laparoscopic versus open liver resection for hepatocellular carcinoma at a North-American Centre: a 2-to-1 matched pair analysis. HPB. 2015;17(4):304-10.

12. Takahara T, Wakabayashi G, Beppu T, et al. Long-term and perioperative outcomes of laparoscopic versus open liver resection for hepatocellular carcinoma with propensity score matching: a multi-institutional Japanese study. J Hepatobiliary Pancreat Sci. 2015;22(10):721-7.
13. Goutte N, Bendersky N, Barbier L, Falissard B, Farges O. Laparoscopic left lateral sectionectomy: a population-based study. HPB (Oxford). 2017;19(2):118-25.

14. Tanaka S, Kubo S, Kanazawa A, et al. Validation of a difficulty scoring system for laparoscopic liver resection: a multicenter analysis by the endoscopic liver surgery study group in Japan. $J$ Am Coll Surg. 2017;225(2):249-58.

15. Kawaguchi Y, Fuks D, Kokudo N, Gayet B. Difficulty of laparoscopic liver resection: proposal for a new classification. Ann Surg. 2018;267(1):13-7.

16. Varley PR, Tohme ST, Chidi AP, et al. Dissemination of minimally invasive liver resection for primary malignancy: reevaluating effectiveness. Ann Surg Oncol. 2017, https://doi.org/ 10.1245/s10434-017-6308-2.

17. Vigano L, Laurent A, Tayar $\mathrm{C}$, et al. The learning curve in laparoscopic liver resection: improved feasibility and reproducibility. Ann Surg. 2009;250(5):772-82.

18. Fretland AA, Dagenborg VJ, Bjørnelv GMW, et al. Laparoscopic versus open resection for colorectal liver metastases: the OSLOCOMET randomized controlled trial. Ann Surg. 2017, https://doi. org/10.1097/sla.0000000000002353. 